\title{
Lipoprotein Metabolism during Acute Inhibition of Hepatic Triglyceride Lipase in the Cynomolgus Monkey
}

\author{
Ira J. Goldberg, Ngoc-Anh le, James R. Paterniti, Jr., Henry N. Ginsberg, \\ Frank T. Lindgren, and W. Virgil Brown, Division of Arteriosclerosis and \\ Metabolism, Mount Sinai School of Medicine, New York, 10029; Donner \\ Laboratory, University of California, Berkeley, California 94720
}

A в S TRACT The role of the enzyme hepatic triglyceride lipase was investigated in a primate model, the cynomolgus monkey. Antisera produced against human postheparin hepatic lipase fully inhibited cynomolgus monkey posttheparin plasma hepatic triglyceride lipase activity. Lipoprotein lipase activity was not inhibited by this antisera. Hepatic triglyceride lipase activity in liver biopsies was decreased by 65$90 \%$ after intravenous infusion of this antisera into the cynomolgus monkey. After a 3-h infusion of the antisera, analytic ultracentrifugation revealed an increase in mass of very low density lipoproteins $\left(S_{\mathrm{f}} 20-\right.$ 400). Very low density lipoprotein triglyceride isolated by isopycnic ultracentrifugation increased by 60 $300 \%$. Analytic ultracentrifugation revealed an increase in mass of lipoproteins with flotation greater than $S_{\mathrm{f}} 9(n=4)$. The total mass of intermediate density lipoproteins $\left(S_{f}, 12-20\right)$ approximately doubled during the $3 \mathrm{~h}$ of in vivo enzyme inhibition. While more rapidly floating low density lipoproteins $\left(\mathrm{S}_{\mathrm{f}} 9\right.$ 12) increased, the total mass of low density lipoproteins decreased after infusion of the antibodies. The changes in high density lipoproteins did not differ from those in control experiments.

In order to determine whether the increases of plasma concentrations of very low density lipoproteins were due to an increase in the rate of synthesis or a decrease in the rate of clearance of these particles, the metabolism of radiolabeled homologous very low density lipoproteins was studied during intravenous infusion of immunoglobulin $G$ prepared from the antisera against hepatic triglyceride lipase $(n=3)$ or preimmune goat sera $(n=3)$. Studies performed in the

\footnotetext{
This work was presented in part at the 73rd Annual Meeting of the American Society for Clinical Investigation, San Francisco, CA, 27 April 1981.

Received for publication 4 February 1982 and in revised form 27 May 1982.
}

same animals during saline infusion were used as controls for each immunoglobulin infusion. There was a twofold increase in the apparent half-life of the very low density lipoprotein apolipoprotein-B tracer in animals receiving the antibody, consistent with a decreased catabolism of very low density lipoproteins. Concomitantly, the rise in low density lipoprotein apoprotein-B specific activity was markedly delayed. None of these changes were observed during infusion of preimmune immunoglobulin G.

Hepatic triglyceride lipase participates with lipoprotein lipase in the hydrolysis of the lipid in very low density lipoproteins, intermediate density lipoproteins, and the larger low density lipoproteins $\left(S_{f} 9-12\right)$. Thus, hepatic triglyceride lipase appears to function in a parallel role with lipoprotein lipase in the conversion of very low density and intermediate density lipoproteins to low density lipoproteins $\left(S_{f} 0-9\right)$.

\section{INTRODUCTION}

Catabolism of circulating triglyceride-rich lipoproteins requires their interaction with lipolytic enzymes available to the plasma space. As a result of this process, chylomicrons are converted to smaller remnant particles before their uptake by the liver (1). Most very low density lipoproteins (VLDL)' are degraded to intermediate density lipoproteins (IDL) and then to low density lipoproteins (LDL) (2). This step-wise catabolism of chylomicrons and VLDL may be mediated

\footnotetext{
${ }^{1}$ Abbreviations used in this paper: Apo-B, apolipoprotein B; $F_{1.20}$, flotation rate in Svedberg units at $d 1.20 \mathrm{~g} / \mathrm{ml} ; \mathrm{HDL}$, high density lipoproteins with $d 1.063-1.21 \mathrm{~g} / \mathrm{ml}$, HTGL, hepatic triglyceride lipase; IDL, intermediate density lipoproteins with $d 1.006-1.019$ or $S_{f} 12-20$, LDL, low density lipoproteins; LPL, lipoprotein lipase; $S_{f}$, flotation rate in Svedberg units at $d 1.063 \mathrm{~g} / \mathrm{ml}$; TMU-tetramethyl urea; VLDL, very low density lipoproteins with $d<1.006$ or $S_{f}$ 20-400.
} 
by more than one enzyme. Two lipolytic enzymes known to be present on the luminal surface of the endothelial cells are lipoprotein lipase and hepatic triglyceride lipase. The function of lipoprotein lipase (LPL) has been studied extensively over the past 25 $\mathrm{yr}$ and it now seems clear that this enzyme is primarily responsible for the hydrolysis of most circulating triglyceride. By contrast, the physiologic function of the hepatic triglyceride lipase is not established.

Hepatic triglyceride lipase (HTGL) is synthesized and secreted primarily by hepatocytes (3). The enzyme is available to interact with circulating lipoproteins after its attachment to the hepatic endothelial surface (4). HTGL is a major component of human postheparin lipolytic activity and, in vitro, has both triglyceride hydrolase (5) and phospholipase A-1 activities (6). Although intact chylomicrons are a poor substrate for this enzyme, HTGL has been shown in vitro to hydrolyze triglyceride in both VLDL and chylomicron remnants (7). Although no primary genetic defect of HTGL has been reported in humans to date, low levels of HTGL activity are found in chronic liver disease (8), hypothyroidism (9), and uremia (10). Abnormal triglyceride-rich lipoproteins are found in the plasma of patients with each of these conditions.

Experimental evidence for the physiologic role of HTGL has been limited to studies in the rat. Immunological inhibition of HTGL in that animal is associated with an increase in high density lipoprotein (HDL) phospholipids (11-13). This has led to the suggestion that HTGL has a role in the conversion of $\mathrm{HDL}_{2}$ to $\mathrm{HDL}_{3}$. In some of these studies, an increase of VLDL triglyceride was noted $(12,13)$. However, these experiments did not determine if this increase in VLDL was the result of a decrease in catabolism or an increase in production. In addition, these data may not be applicable to human metabolism, since in rats, most of the circulating VLDL is removed from the plasma without conversion to LDL (14). In humans, the conversion of IDL to LDL has recently been demonstrated to occur primarily across the splanchnic bed (15). Thus, an enzyme located in the liver may be involved in a pathway involving VLDL catabolism and LDL production. The cynomolgus monkey is an appropriate animal in which to study the role of HTGL, since monkeys, like humans, convert most VLDL to LDL (16). They also maintain LDL levels that are comparable to human levels. Experiments were designed to determine the changes in lipoprotein levels and composition that might occur during acute inhibition of HTGL in cynomolgus monkeys. In addition, kinetic studies of the metabolism of VLDL apolipoprotein B (apo-B) were performed to determine whether the alterations in lipoproteins were associated with a change in VLDL catabolism.

\section{METHODS}

Animals. Adult cynomolgus monkeys, females $(3-4 \mathrm{~kg})$ and males $(4-5 \mathrm{~kg})$, were maintained on a chow diet containing 5\% fat (Ralston Purina, St. Louis, MO). The animals were fasted for 12-14 h before each study. Monkeys were anesthetized with intramuscular ketamine $10 \mathrm{mg} / \mathrm{kg}$ (ParkeDavis Company, Morris Plains, NJ) for liver biopsies or insertion of intravenous catheters. For studies of lipoprotein profiles or lipoprotein turnover the animals were restrained in a monkey chair and allowed to revive from anesthesia.

A total of 11 experimental animals were studied according to three different protocols involving (1) infusion of the antibody in conjunction with serial liver biopsies $(n=3),(2)$ serial sampling for analysis of lipoproteins by analytical and/ or isopycnic ultracentrifugation $(n=5)$ and (3) turnover studies using radioactive VLDL $(n=3)$. An additional 10 animals received a preimmune goat immunoglobulin instead of the antibody. They were studied as above and served as controls. None of these 21 animals was used in more than one protocol

In vitro studies. Postheparin plasma was obtained from normal human volunteers $15 \mathrm{~min}$ after intravenous injection of $60 \mathrm{~L} / \mathrm{kg}$ of heparin (Riker Laboratories, Northridge, CA) and from cynomolgus monkeys $10 \mathrm{~min}$ after $100 \mathrm{U} / \mathrm{kg}$ of heparin. Human HTGL was partially purified and anti-human HTGL, antiserum was produced in a goat as previously reported (17). In vitro assay of human postheparin plasma demonstrated comparable levels of activity after pretreatment with the antibody or with $50 \mathrm{mM}$ sodium dodecyl sulfate (18) using a gum-arabic stabilized emulsion of tri$\left(\mathbf{H}^{3}\right)$ oleoylglycerol (New England Nuclear, Boston, MA). When assayed in postheparin plasma under conditions that inhibit LPL but optimize HTGL activity (pH 8.8, $1 \mathrm{M} \mathrm{NaCl}$ ) (18), addition of $1 / 10 \mathrm{vol}$ of the antisera reduced the lipolytic activity by $>90 \%$. This inhibition did not require preincubation or centrifugation of the putative immune complex, suggesting that inactivation of HTGL occurs as a result of binding by the antibody at or near the active site.

To reduce possible nonspecific reactions of goat serum during in vivo experiments, an IgG fraction of the antiserum and of preimmune goat serum was prepared using sodium sulfate precipitation (19). The IgG was dialyzed against sterile $0.15 \mathrm{M} \mathrm{NaCl}$ containing $0.1 \%$ EDTA (pH 7.4). The goat IgG (both immune and preimmune) was treated by incubation at $4^{\circ} \mathrm{C}$ with Sepharose beads containing covalently bound whole monkey plasma (preheparin) to absorb nonspecific reactants. This procedure did not reduce the reactivity of the antisera against HTGL activity. Before absorption, two lines were seen on double diffusion studies with monkey sera, and these disappeared after this procedure. All IgG preparations were assayed for total protein and in vitro activity against HTGL using an artificial emulsion before their use in the monkeys.

To determine the specificity of the anti-HTGL IgG preparation, a natural substrate was used. The triglyceride in human VLDL was radiolabeled with tri- $\left(\mathbf{H}^{3}\right)$ oleoylglycerol using the method of Fielding (20). Human HTGL and LPL were partially purified by heparin-Sepharose chromatography (21). These enzyme solutions and cynomolgus monkey postheparin plasma lipase activities were assayed in a 0.5 $\mathrm{ml}$ assay mixture containing $0.5 \mathrm{mg}$ human VLDL triglyceride $(0.1 \mu \mathrm{Ci} / \mathrm{mg}), 0.16 \mathrm{M} \mathrm{NaCL}, 12.5 \%$ bovine serum albumin, and $0.35 \mathrm{M}$ tris- $\mathrm{HCl}$, pH 7.4. Monkey postheparin plasma was also preincubated $30 \mathrm{~min}$ at $27^{\circ} \mathrm{C}, 1.0 \mathrm{M} \mathrm{NaCL}$, pH 8.8, to completely inhibit LPL and the remaining HTGL activity was then assayed in a solution containing $1.25 \mathrm{M}$ 
$\mathrm{NaCl}, 8.3 \%$ bovine serum albumin, $0.233 \mathrm{M}$ tris- $\mathrm{HCl}, \mathrm{pH}$ 8.8. The VLDL substrate was identical to that used for the assay of human enzyme solutions. The enzyme solutions were mixed with increasing volumes of the IgG prepared from the antisera and were then added to the VLDL solution (Fig. 1). The assays were then incubated for $60 \mathrm{~min}$ at $27^{\circ} \mathrm{C}$. Hydrolyzed free fatty acids were extracted and activity was calculated as previously described (18). All assays were performed in triplicate.

Liver biopsies. Documentation that intravenous infusion of the antibody produced inhibition of HTGL in hepatic tissue was obtained using percutaneous liver biopsy specimens. The assay was initially developed using a homogenate of cynomolgus monkey liver prepared in buffer containing $0.01 \mathrm{M}$ phosphate $(\mathrm{pH} \mathrm{7.4)}$ ) and $0.15 \mathrm{M} \mathrm{NaCl}$ (PBS), and 0.2 $\mathrm{U} / \mathrm{ml}$ heparin. Lipolytic activity was assayed in aliquots of this homogenate using $0.45 \mathrm{ml}$ of gum arabic emulsion containing $5 \mu \mathrm{mol}$ of trioleoylglycerol $(10 \mu \mathrm{Ci} / \mathrm{ml})$ as previously described (17). Protein in the liver homogenate was measured by the method of Lowry et al. (22) using bovine serum albumin as a standard. The lipase activity was linear with increasing quantities of homogenate containing from 5 to $30 \mu \mathrm{g}$ of protein. This activity could be completely inhibited in vitro by treatment of the homogenate with an equal volume of goat anti-human HTGL serum. No inhibition was found after incubation with preimmune goat sera.

Immediately before injection, each preparation of IgG (prepared as described above) was filtered through a $0.45-$ $\mu \mathrm{m}$ filter (Millipore Corp., Bedford, MA) and centrifuged $2 \mathrm{~h}$ at $49,000 \mathrm{rpm}$ in an $\mathrm{SW} 50$ rotor to remove aggregates.

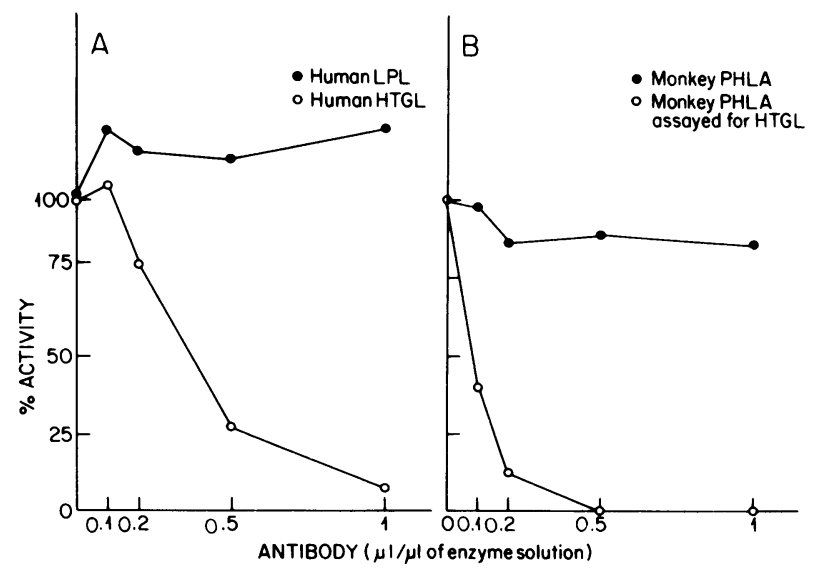

Figure 1 In vitro assay of anti-HTGL IgG assayed using emulsions containing tri- $\left[\mathrm{H}^{3}\right]$ oleoyglycerol in human VLDL (see Methods). A. Solutions of human HTGL $(1.13 \mu \mathrm{mol}$ of free fatty acids $/ \mathrm{ml}$ per h) and human LPL $(0.56 \mu \mathrm{mol}$ of free fatty acids $/ \mathrm{ml}$ per h) separated by heparin-sepharose chromatography were assayed with increasing amounts of anti-HTGL IgG $(7 \mathrm{mg} / \mathrm{ml})$. Activity at $100 \%$ in each assay was 11.2 and $56.5 \mathrm{nmol}$ of free fatty acids/h for LPL and HTGL, respectively. B. Monkey postheparin plasma containing lipase activity releasing $2 \mu \mathrm{mol}$ free fatty acids $/ \mathrm{ml}$ per $\mathrm{h}$ was assayed as total lipolytic activity and after preincubation in $1.0 \mathrm{M} \mathrm{NaCl}, 27^{\circ} \mathrm{C}, 30 \mathrm{~min}$, a condition that inactivates LPL, $(0.17 \mu \mathrm{mol}$ free fatty acid $/ \mathrm{ml}$ per $\mathrm{h})$ with increasing amounts of anti-HTGL IgG. $100 \%$ activity was $40 \mathrm{nmol}$ and $5.4 \mathrm{nmol}$ free fatty acid/h for total postheparin lipolytic activity and HTGL activity, respectively.
Cynomolgus monkeys were given a single rapid intravenous injection of $20 \mathrm{mg} / \mathrm{kg}$ of anti-HTGL IgG or of nonimmune goat IgG both at concentrations of $10-15 \mathrm{mg} / \mathrm{ml}$. Percutaneous liver biopsies were obtained in duplicate (two biopsies within $2 \mathrm{~min}$ ) using a Menghini needle before and for up to $3 \mathrm{~h}$ after IgG infusion. The biopsies were washed $\left(4^{\circ} \mathrm{C}\right)$ in $1 \mathrm{ml}$ of PBS, blotted on gauze, and weighed on a micro balance (Cahn Instruments, Cerritos, CA). The biopsies (5$25 \mathrm{mg}$ wet $\mathrm{wt}$ ) were placed in $150 \mu \mathrm{l}$ of PBS containing 10 $\mathrm{U}$ heparin $/ \mathrm{ml}$ and frozen $\left(-70^{\circ} \mathrm{C}\right)$ until assayed. After defrosting, the biopsies were homogenized by passage of the material repeatedly through a 19 -gauge needle using a tuberculin syringe. The effluent was then sequentially forced through a 21 - and a 23-gauge needle before assay. 100- $\mu$ l aliquots of homogenate were then assayed. The biopsy activity expressed per milligram of wet weight was linearly related to activity as expressed per milligram of homogenate protein. While a single intravenous bolus of anti-HTGL IgG inhibited the lipase activity, to assure maximal suppression throughout the study, an additional $20 \mathrm{mg} / \mathrm{kg}$ of anti-HTGL $\lg G$ was administered as a continuous infusion over the subsequent $3 \mathrm{~h}$. This protocol was used for all subsequent experiments. Postheparin plasma LPL activity measured at the end of the infusion of anti-HTGL IgG was comparable to that obtained one day previously without IgG infusion. Rectal temperature and blood pressure were determined by hourly monitoring and were unchanged by the infusion of the IgG preparations.

Measurement of changes in lipoprotein mass. Animals were studied during infusion of anti-HTGL $\operatorname{IgG}(n=5)$ and in control experiments with saline or preimmune goat IgG $(n=5)$. Hourly blood samples, $(1.0 \mathrm{ml})$, were taken for $3-$ $4 \mathrm{~h}$ before beginning the infusion to determine total plasma triglyceride and cholesterol. Enzymatic methods were used (ABA 100, Abbott Laboratories, Chicago, IL). Animals were considered to be in steady state if the plasma triglyceride and cholesterol did not change $>10 \%$ during the $2 \mathrm{~h}$ preceding the study. Plasma samples for measurement of total plasma triglyceride and cholesterol (1-ml samples) were taken immediately before the injection of IgG. Larger samples $(6-10 \mathrm{ml})$ were obtained at $5 \mathrm{~min}$ and at 1 and $3 \mathrm{~h}$ after the injection. After the initial four animals were studied, changes at $1 \mathrm{~h}$ were found to be similar, but less marked, than those at $3 \mathrm{~h}$. The l-h sampling was thus omitted to preserve blood volume in subsequent studies. In three control and three experimental animals, lipoprotein fractions were isolated from these larger samples by ultracentrifugation in the 40.3 rotor (Beckman Instruments, Inc., Palo Alto, CA) $39,000 \mathrm{rpm} \times 24 \mathrm{~h}, \quad 10^{\circ} \mathrm{C}(23)$. VLDL $(d<1.006)$, IDL (1.006-1.019), LDL (1.019-1.063), $\mathrm{HDL}_{2}(1.063-1.12), \mathrm{HDL}_{3}$ (1.12-1.21) were thus obtained, and subsequently analyzed for triglyceride, cholesterol, and protein. After extraction by the method of Bligh and Dyer (24) and digestion with perchloric acid (25), total phospholipids were estimated by determination of inorganic phosphorus using malachite green (Eastman Chemicals, Rochester, NY) (26), and multiplication of this value by 25 .

Analytical ultracentrifugation of the plasma from four experimental and three control animals was performed at the Donner Laboratory. The concentrations of the serum lipoproteins and their distribution as a function of flotation rate $\left(S_{f}{ }^{\circ}\right.$ or $\left.F_{1.20}\right)$ were determined by computerized analysis of data from the schlieren patterns of analytical ultracentrifuge runs at $52,640 \mathrm{rpm}$ of the isolated fraction containing L.DL, IDL, and VLDL in a base-line solution of $d 1.063 \mathrm{~g} /$ $\mathrm{ml}$ and the isolated HDL in a solution of $d 1.20 \mathrm{~g} / \mathrm{ml}(27)$. The flotation rates determined by a " $n F^{\circ}$ vs. $p$ " technique 
(28), are expressed in Svedbergs $\left(10^{-13} \mathrm{~cm} \mathrm{~S}^{-1} \mathrm{dyn}^{-1} \mathrm{~g}^{-1}\right)$ and are corrected for concentration dependence and to standard conditions ( $\mathrm{T}=26^{\circ} \mathrm{C}$ ).

Studies of VIDL apo-B kinetics. Four to six female monkeys (not used for previous studies) were plasmapheresed, and 100-200 ml of plasma were collected into sterile tubes. VLDI, was isolated by ultracentrifugation at $d=1.006$ in an SW 28 rotor at $26.000 \mathrm{rpm}, 48 \mathrm{~h}, 10^{\circ} \mathrm{C}$. The VI.DI, was concentrated by a second ultracentrifugation in an SW 60 rotor at $55,000 \mathrm{rpm}$ for $18 \mathrm{~h}$. After dialysis against $0.15 \mathrm{M} \mathrm{NaCl}, \mathrm{pH} 7.4$, the VLDL preparation was divided and one aliquot ( $1 \mathrm{mg}$ protein) was radioiodinated with ${ }^{125} \mathrm{I}$ and a second aliquot with ${ }^{131}$ I (New England Nuclear) by the method of McFarlane (29) as modified by Bilheimer et al. (30). The radioiodinated lipoproteins were extensively dialyzed against $0.15 \mathrm{M} \mathrm{NaCl}, \mathrm{pH} 7.4,0.1 \%$ EDTA to remove free iodine and filtered $(0.45 \mu \mathrm{m}$ Millipore) before injection. The iodinated VLDL preparations were used within $3 \mathrm{~d}$ of labeling. The injected VLDL contained 50-75 $\mu \mathrm{g}$ of total protein and $10-20 \mu \mathrm{Ci}$ of radioactivity. Animals received a few drops of a saturated solution of potassium iodide in their drinking water for the week before each turnover study to prevent thyroidal uptake of radioactive iodine.

After intravenous injection of radioiodinated VLDL, blood samples $(1.5-2.0 \mathrm{ml})$ were obtained from a separate site at $5,15,30 \mathrm{~min}$ and $\mathrm{l}, 3,6$, and $9 \mathrm{~h}$. The next day, an $\operatorname{IgC}$ bolus was injected as described above and $30 \mathrm{~min}$ later the VLDL containing the alternate iodine tracer $\left({ }^{125} \mathrm{I}\right.$ or $\left.{ }^{1.31} \mathrm{I}\right)$ was injected intravenously. Additional $\operatorname{IgG}$ was infused $(20$ $\mathrm{mg} / \mathrm{kg}$ ) over the subsequent $3 \mathrm{~h}$. Blood was obtained as in the study the previous day. All blood samples were collected into tubes containing EDTA $(3 \mathrm{mg} / \mathrm{ml})$ and stored at $4^{\circ} \mathrm{C}$ after centrifugation to remove cells. A $150-\mu l$ aliquot of plasma was set aside for cholesterol and triglyceride measurements and $1 \mathrm{ml}$ of plasma was used to isolate VLDL, IDI, and LDI, in the 40.3 rotor as described above.

A po-B specific activity in VLDL and IDL, was determined using the method of Le et al. (31). Samples $(0.9 \mathrm{ml})$ were delipidated sequentially with acetone $(3 \mathrm{ml})$ and isopropyl alcohol $(3 \mathrm{ml})$. The protein was solubilized with $1 \mathrm{ml}$ of 9 M tetramethyl urea (TMU) (Burdick-Jackson Laboratories, Muskegon, MI) at room temperature for $1 \mathrm{~h}$. Apo-B was selectively precipitated by addition of $1 \mathrm{ml}$ of water and centrifugation at $300 \mathrm{~g}$ for $45 \mathrm{~min}$. The supernatant was aspirated and the pellet washed with $3 \mathrm{ml}$ of water to remove any remaining TMU. Radioactivity was determined using an autogamma scintillation spectrometer (Packard Instruments, Inc., Downers (Grove, IL) and corrections made for crossover of radioactivity from ${ }^{131} 1$ as measured in the ${ }^{125} I$ channel. Protein in each tube was determined (22) and specific activity calculated. LDL apo-B specific activity was estimated as radioactivity divided by total I.DL protein.

\section{RESULTS}

Antibody activity. The specificity of the inhibition was confirmed by incubation of partially purified human HTGL with an IgG preparation of the anti-HTGL sera. This completely inhibited lipolytic activity measured using radiolabeled triglyceride in human VLDL at physiologic pH (7.4) (Fig. 1). LPI activity was not inhibited by the antibody. Cynomolgus monkey postheparin plasma measured under similar conditions was inhibited $\sim 12 \%$ by the IgG (Fig. 1B). This decrease in activity is approximately that expected resulting from inhibition of the HTGL activity in the assayed plasma. To inhibit the LPL activity, monkey postheparin plasma was preincubated in $1.0 \mathrm{M} \mathrm{NaCl}$ for 30 min and then assayed under optimal conditions for HTGL (19). The postheparin plasma lipase activity assayed in this manner, which should have contained predominantly HTGL activity, was completely inhibited by the antibody.

The intravenous bolus of anti-HTGL IgG inhibited the hepatic triglyceride lipase activity in monkey liver biopsies by 65 to $90 \%$ (Fig. 2). The suppression was maintained for over $3 \mathrm{~h}$ by the infusion of the IgG. No change in lipase activity was found in similar hepatic biopsies obtained from animals receiving either preimmune goat $\operatorname{IgG}(20 \mathrm{mg} / \mathrm{kg})$ or normal saline.

Lipoprotein masses. Analytical ultracentrifugation showed a marked rise in total VLDL mass in all animals studied after anti HTGL IgG (Fig. 3), with the greatest increase confined to the $S_{f}$ 20-100 range (Fig. 4 , Table I). The more rapidly floating VLDL $\left(\mathrm{S}_{\mathrm{f}} 100-\right.$ 400) also increased in three of four animals. A consistent increase was also found in the $S_{\mathrm{f}}$ 12-20 lipoproteins (Table $\mathrm{I}$ ). The $\mathrm{S}_{\mathrm{f}}$ 0-12 fraction (LDL) fell in all animals receiving anti-HTGL IgG. Difference plots from each of these four animals (Fig. 4) showed that this fall was due to a decline in the more dense fraction $\left(S_{\mathrm{f}} 0-9\right)$. In contrast, the $S_{\mathrm{f}}$ 9-12 lipoproteins increased in all four animals after inhibition of HTGL. The three control animals showed no increase in VLDL (Fig. 3) and inconsistent changes in IDL and LDL. Analytical

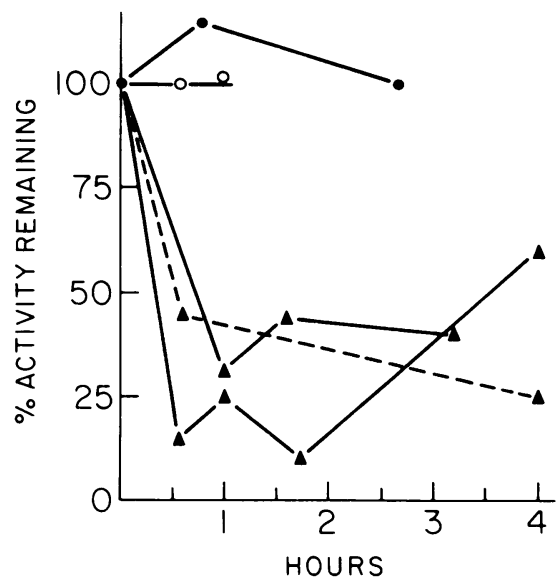

FIGURE 2 In vivo inhibition of hepatic triglyceride lipase activity. Liver biopsies were obtained at the times indicated after a single intravenous injection into the monkey of 20 $\mathrm{mg} / \mathrm{kg}$ of goat anti human HTGL IgG $\Delta-\Delta$, preimmune goat IgG $-\bullet$, and saline $\bigcirc-O$. $--\Delta$ indicates the activity measured after a bolus injection of IgG $(20 \mathrm{mg} /$ $\mathrm{kg}$ ) followed by an equal amount of $\operatorname{lgG}$ infused over the ensuing $3 \mathrm{~h}$. Results are of duplicate liver biopsies, homogenized and assayed for triglyceride lipase as described in Methods. 
TABLE I

Lipoprotein Mass Profiles by Analytic Ultracentrifugation before and after Anti-HTGL IgG Infusion ( $\mathrm{mg} / \mathrm{dl}$ )

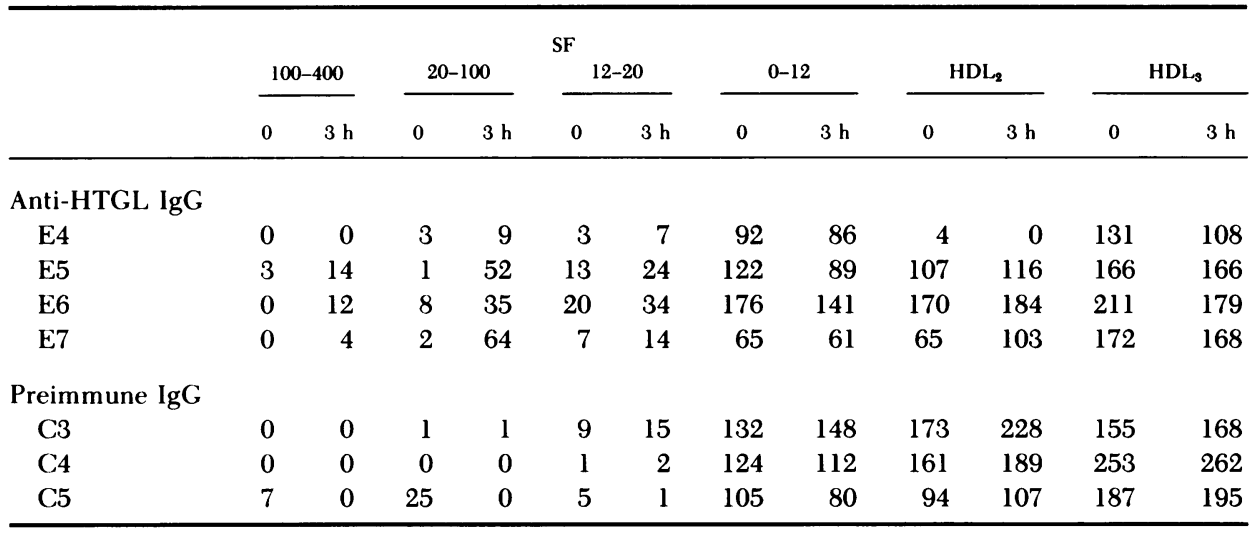

ultracentrifugation demonstrated an increase in $\mathrm{HDL}_{2}$ mass in three of four animals. However, in all three control animals, increases in $\mathrm{HDL}_{2}$ mass of similar magnitude were observed.

The values for protein and lipids in VLDL and LDL from monkeys E-5, E-6 and E-8 are shown in Table II. VLDL triglycerides increased in all three animals with changes ranging from $60-300 \%$. Similar increases were noted in the phospholipid content $(50-380 \%)$. Animals receiving preimmune goat IgG (C-4, C-6, C7) had no increase in VLDL lipids or protein. The IDL, as isolated by equilibrium ultracentrifugation $(d$ 1.006-

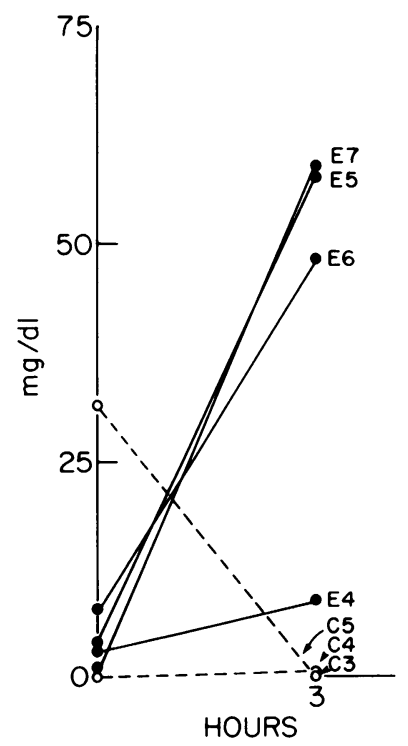

Figure 3 VLDL mass as determined by analytic ultracentrifugation before and after intravenous infusion of antiHTGL IgG (E-4, E-5, E-6, E-7) and preimmune goat IgG (C-3, C-4, C-5).
1.019), showed no consistent change in the mass of any component. The LDL cholesterol fell in both control and experimental animals. In the control, but not experimental monkeys, this was accompanied by a fall in LDL triglycerides. The $\mathrm{HDL}_{2}$ phospholipid increased in all three experimental and two of three con-
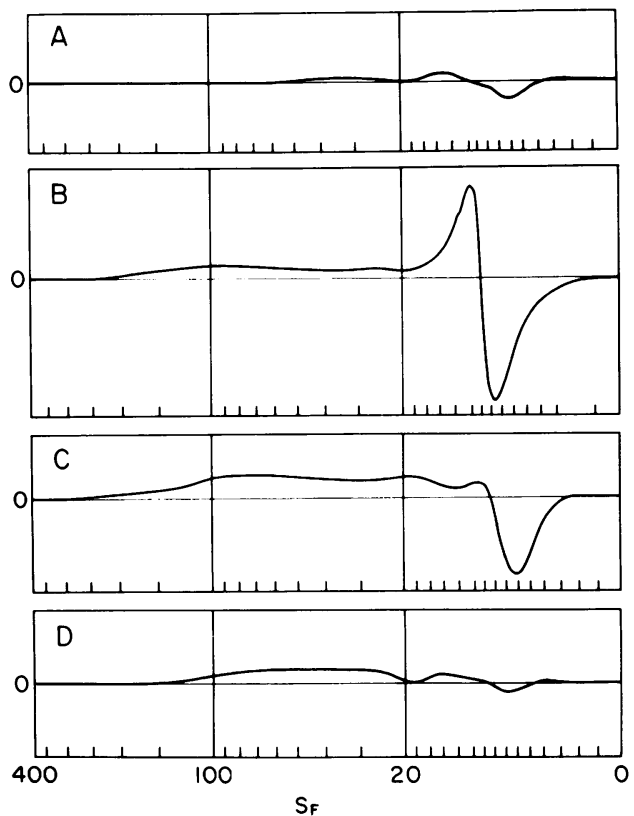

Figure 4 Difference plots illustrating changes in serum lipoprotein profiles after infusion of anti-HTGL IgG in four monkeys (A-E4, B-E5, C-E6, D-E7). The base-line analytical ultracentrifugal analysis is subtracted from the analysis of the sample obtained $3 \mathrm{~h}$ after beginning the antibody infusion. Deflections above the zero line indicate an increase in mass, whereas deflections below the line illustrate a loss of mass. The increases are of lipoproteins of $S_{f} 9-400$, whereas lipoproteins of $S_{f} 0-9$ are decreased.

1188 Goldberg, Le, Paterniti, Ginsberg, Lindgren, and Brown 
TABLE II

$V L D L$ and LDL Composition ( $\mathrm{mg} / \mathrm{dl}$ ) before and after HTGL $\operatorname{IgG}($ A) or Preimmune Goat IgG (B)

\begin{tabular}{|c|c|c|c|c|c|c|c|}
\hline \multicolumn{2}{|c|}{ TG } & \multicolumn{2}{|c|}{$\mathrm{Chol}^{\circ}$} & \multicolumn{2}{|c|}{$\mathrm{PL}^{\bullet}$} & \multicolumn{2}{|c|}{ Protein } \\
\hline 0 & $3 \mathrm{~h}$ & 0 & $3 \mathrm{~h}$ & 0 & $3 \mathrm{~h}$ & 0 & $3 \mathrm{~h}$ \\
\hline
\end{tabular}

A VLDL

Animals receiving anti-HTGL IgG

$\begin{array}{rrrrrrrrr}\text { E5 } & 10 & 16 & 1 & 1 & 1.7 & 2.5 & 4.1 & 4.7 \\ \text { E6 } & 8 & 32 & 1 & 8 & 1.4 & 6.8 & 4.4 & 10.3 \\ \text { E8 } & 5 & 8 & 1 & 1 & 0.6 & 1.2 & 2.8 & 4.6\end{array}$

Animals receiving preimmune goat $\operatorname{IgC}$

$\begin{array}{lllllllll}\text { C4 } & 10 & 11 & 2 & 2 & 2.0 & 2.6 & 4.1 & 5.3 \\ \text { C6 } & 10 & 12 & 1 & 1 & 1.8 & 2.0 & 2.9 & 3.2 \\ \text { C7 } & 25 & 11 & 2 & 1 & 3.6 & 1.3 & 4.2 & 2.6\end{array}$

B LDL

Animals receiving anti-HTGL IgG

$\begin{array}{lllllllll}\text { E5 } & 7 & 7 & 71 & 50 & 30 & 30 & 59 & 48 \\ \text { E6 } & 5 & 7 & 27 & 22 & 24 & 20 & 64 & 69 \\ \text { E8 } & 6 & 8 & 57 & 51 & 27 & 20 & 66 & 54\end{array}$

Animals receiving preimmune goat IgG

\begin{tabular}{lrlllllll} 
C4 & 8 & 8 & 62 & 53 & 37 & 30 & 47 & 49 \\
C6 & 10 & 7 & 38 & 24 & 27 & 22 & 30 & 23 \\
C7 & 9 & 6 & 26 & 19 & 20 & 17 & 24 & 20 \\
\hline
\end{tabular}

- TG, triglycerides; Chol, cholesterol; PL, phospholipids.

trol animals when examined $3 \mathrm{~h}$ after IgG infusion (Table III). There were no other consistent changes in the composition of $\mathrm{HDL}_{2}$ or $\mathrm{HDL}_{3}$. Reflecting the VLDL increase, total plasma triglyceride values increased in each of the five monkeys receiving antiHTGL IgG, producing a rise for this lipid of 16-140\% (Table IV). A small fall in total plasma cholesterol was found in both treated and control animals.

VLDL apolipoprotein B metabolism. The effects of anti-HTGL IgG infusion on the metabolism of apo$B$ in VLDL, IDL and LDL were studied by intravenous injection of radiolabeled VLDL. As a representative experiment, the specific activities of apo-B in all three lipoproteins from monkeys E9 and C8 during $6 \mathrm{~h}$ of saline infusion are shown in the first panel of Figs. 5A and $5 \mathrm{~B}$, respectively. In six monkeys studied, the specific activity of apo-B in IDL and LDL rose rapidly, reaching a peak within the first hour during these baseline experiments with saline infusion (Table V). The metabolism of a second VLDL tracer, which was injected into monkey E-9 during infusion of anti-HTGL IgG, is also shown in Fig. 5A (right panel). In this and two additional experiments, (monkeys E-10 and E-11),
TABLE III

HDL Compositional Changes ( $\mathrm{mg} / \mathrm{dl}$ ) Base line and after Anti-HTGL IgG (A) Or Preimmune Goat IgG (B)

\begin{tabular}{|c|c|c|c|c|c|c|c|}
\hline \multicolumn{2}{|c|}{$\mathrm{TG}^{\circ}$} & \multicolumn{2}{|c|}{ Chol $^{\bullet}$} & \multicolumn{2}{|c|}{$P^{*}$} & \multicolumn{2}{|c|}{ Protein } \\
\hline 0 & $3 \mathrm{~h}$ & 0 & $3 \mathrm{~h}$ & 0 & $3 \mathrm{~h}$ & 0 & $3 \mathrm{~h}$ \\
\hline
\end{tabular}

A HDI,

Animals receiving anti-HTGL IgG

$\begin{array}{rrrrrrrrr}\text { E5 } & 7 & 8 & 37 & 37 & 54 & 60 & 115 & 113 \\ \text { E6 } & 6 & 8 & 15 & 16 & 36 & 46 & 81 & 91 \\ \text { E8 } & 5 & 5 & 36 & 40 & 12 & 14 & 108 & 110\end{array}$

Animals receiving preimmune goat $\mathrm{IgG}$

$\begin{array}{rrrrrrrrr}\text { C4 } & 7 & 12 & 54 & 58 & 112 & 116 & 140 & 157 \\ \text { C6 } & 7 & 8 & 25 & 28 & 48 & 57 & 57 & 59 \\ \text { C7 } & 7 & 5 & 30 & 29 & 57 & 49 & 44 & 51\end{array}$

B $\mathrm{HDL}_{3}$ Animals receiving anti-HTGL IgG

$\begin{array}{rrrrrrrrr}\text { E5 } & 2 & 5 & 13 & 10 & 21 & 20 & 196 & 159 \\ \text { E6 } & 6 & 8 & 5 & 9 & 22 & 20 & 255 & 241 \\ \text { E8 } & 2 & 4 & 11 & 12 & 39 & 38 & 102 & 99\end{array}$

Animals receiving preimmune goat IgG

\begin{tabular}{rrrrrrrrr} 
C4 & 2 & 4 & 26 & 26 & 43 & 49 & 156 & 149 \\
$\mathrm{C} 6$ & 16 & 12 & 44 & 33 & 30 & 28 & 41 & 44 \\
$\mathrm{C} 7$ & 16 & 15 & 30 & 35 & 26 & 31 & 34 & 46 \\
\hline
\end{tabular}

- TG, triglycerides; Chol, cholesterol; PL, phospholipids.

TABLE IV

Triglyceride and Cholesterol $(\mathrm{mg} / \mathrm{dl})$ Levels after Anti-HTGL IgG

\begin{tabular}{|c|c|c|c|}
\hline \multicolumn{2}{|c|}{ Triglyceride } & \multicolumn{2}{|c|}{ Cholesterol } \\
\hline 0 & $3 \mathrm{~h}$ & 0 & $3 \mathrm{~h}$ \\
\hline
\end{tabular}

Anti-HTGL IgG

\begin{tabular}{lrrrr} 
E4 & 52 & 61 & 63 & 67 \\
E5 & 48 & 57 & 136 & 115 \\
E6 & 52 & 125 & 92 & 85 \\
E7 & 35 & 42 & 144 & 117 \\
E8 & 54 & 93 & 90 & 79 \\
& & & & \\
Control & & & & \\
$\mathrm{C}^{\circ}$ & 67 & 49 & 131 & 116 \\
$\mathrm{C}^{\circ}$ & 57 & 64 & 127 & 130 \\
$\mathrm{C}^{\circ}$ & 65 & 68 & 124 & 110 \\
$\mathrm{C} 7^{\circ}$ & 92 & 81 & 99 & 93 \\
$\mathrm{C} 81$ & 47 & 40 & 89 & 81 \\
$\mathrm{C} 9 \downarrow$ & 87 & 78 & 108 & 107 \\
\hline
\end{tabular}

- Received intravenous preimmune IgG.

† Received intravenous saline. 


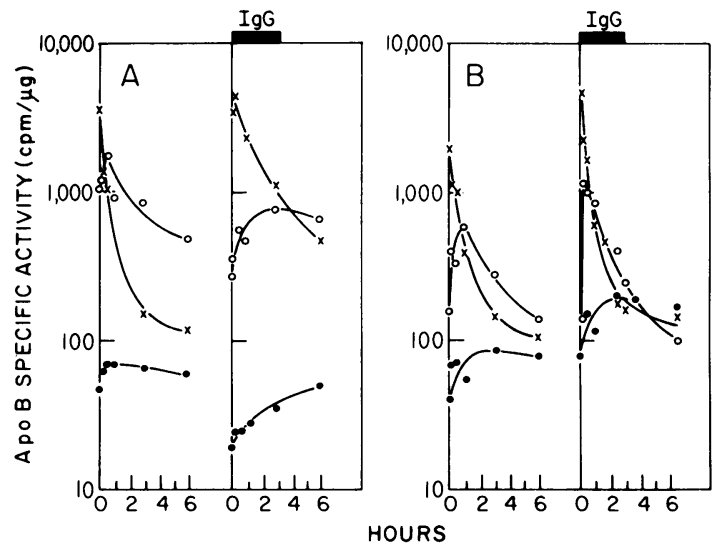

Figure 5 Effect of anti-HTGL IgG (A) and preimmune goat IgG (B) on VLDL apo-B metabolism. Specific activity of apo-B in VLDL $\times \times \times$, IDL OOO, and LDL 000 after intravenous injection of radiolabeled VLDL is graphed vs. time. A base-line study performed in each animal during infusion of saline is shown ( $A$ and $B$ right panels). The same VLDL preparation labeled with a different isotope, was used for a study during an IgG infusion the following day in each animal (left panels). The anti-HTGL IgG study (A) illustrated was performed using animal E9 and the preimmune IgG study (B) illustrated is from monkey C8. The bar above the graphs indicates the period during infusion of IgG

the VLDL apo-B specific activity fell more slowly during the inhibition of HTGL (Table V). After the antibody infusion, the increase to peak specific activity in IDL was markedly retarded reaching a maximum at $\sim 3 \mathrm{~h}$. The peak specific activity for LDL was observed between 3 and $6 \mathrm{~h}$. In the three control experiments (monkeys C-8, C-9, and C-10) nonimmune IgG was infused. No evidence for slowing in the clearance of VLDL or for a delay in the conversion of VLDL
apo-B to IDL and to LDL was found (Fig. 5B and Table V). The apparent half life of apo-B in VLDL increased from $0.47 \pm 0.06$ to $1.0 \pm 0.43 \mathrm{~h}(x \pm \mathrm{SD})$ in the HTGL inhibited animals. By contrast, the half-life of VLDL apo-B tracer in control animals decreased slightly from $0.47 \pm 0.15$ to $0.33 \pm 0.08 \mathrm{~h}$.

\section{DISCUSSION}

In the present studies, acute inhibition of HTGL in the cynomolgus monkey produced a rise in the mass of VLDL $\left(\mathrm{S}_{\mathrm{f}}>20\right)$, IDL $\left(\mathrm{S}_{\mathrm{f}} 12-20\right)$ and a subclass of $\operatorname{LDL}\left(S_{\mathrm{f}} 9-12\right)$. The smaller, more dense LDL $\left(S_{\mathrm{f}} 0-9\right)$ decreased and, as a result, the total LDL level fell. These data taken together with the specific activity curves of apo-B obtained following injection of radiolabeled VLDL, strongly support the hypothesis that in this primate, HTGL facilitates the degradation of VLDL and IDL and their subsequent conversion to LDL. Since lipoprotein lipase was not inhibited in vitro or in the postheparin plasma of animals receiving an infusion of anti-HTGL IgG, it seems safe to assume that lipoprotein lipase was active in vivo during all experiments. The continuing degradation of VLDL and the conversion to LDL observed during the turnover studies was probably due to the action of LPL. It is also possible that some residual HTGL activity was present in vivo, since intravenous infusion of the antibody produced $65-90 \%$ suppression of the baseline activity when measured in homogenates of liver biopsies. However, it is believed that this residual activity represented intracellular enzyme that was not available to the circulating IgG molecules. Such an assumption is consistent with previous estimates that $25 \%$ of HTGL activity is present within rat hepatocytes (12).

TABLE V

VLDL Apo-B Kinetics during Intravenous Infusion of Saline and Either Anti-HTGL or Preimmune IgG

\begin{tabular}{|c|c|c|c|c|c|c|}
\hline & \multicolumn{2}{|c|}{ VLDL apo-B half life (h) } & \multicolumn{2}{|c|}{ Peak IDL apo-B specific activity (h) } & \multicolumn{2}{|c|}{ Peak L.DL, apo-B specific activity (h) } \\
\hline & Saline & $\lg G$ & Saline & $\lg$; & Saline & $\lg C$ \\
\hline \multicolumn{7}{|c|}{ A Monkeys receiving anti-HTGL IgG } \\
\hline E9 & 0.50 & 0.75 & 0.5 & 3.0 & 3.0 & 6.0 \\
\hline E10 & 0.50 & 1.50 & 1.0 & 3.0 & 1.0 & 6.0 \\
\hline E11 & 0.42 & 0.75 & 0.5 & 1.75 & 3.0 & 3.0 \\
\hline Mean \pm SD & $0.47 \pm 0.05$ & $1.0 \pm 0.43$ & $0.67 \pm 0.28$ & $2.58 \pm 0.72$ & $1.42 \pm 1.24$ & $5.0 \pm 0.173$ \\
\hline \multicolumn{7}{|c|}{ B Monkeys receiving preimmune IgG } \\
\hline $\mathrm{C} 8$ & 0.60 & 0.40 & 1.2 & 1.25 & 3.0 & 2.0 \\
\hline C9 & 0.50 & 0.25 & 1.0 & 0.5 & 3.0 & 3.0 \\
\hline $\mathrm{ClO}$ & 0.30 & 0.35 & 1.0 & 0.3 & 3.0 & 2.0 \\
\hline Mean \pm SD & $0.47 \pm 0.15$ & $0.33 \pm 0.08$ & $1.07 \pm 0.15$ & $0.68 \pm 0.50$ & 3.0 & $2.33 \pm 0.58$ \\
\hline
\end{tabular}


After inhibition of HTGL, an increase was found in VLDL triglycerides, cholesterol, and phospholipids, giving no indication as to which lipid component of this lipoprotein might be the primary substrate for the enzyme. The decreased clearance of radiolabeled apo$B$ in VLDL confirmed that these mass changes were, in fact, due to inhibition of the degradation of VLDL particles and not the result of an increase in VLDL secretion. The observed doubling of the half-life of the VLDL tracer should have resulted in a twofold increase in the concentration of plasma VLDL. Thus the increases in VLDL lipids and proteins were appropriate for the degree of inhibition of VLDL catabolism.

The appearance of radiolabeled apo-B in IDL after injection of ${ }^{125}$ I-VLDL was consistent with the reduced clearance of VLDL noted above. The rate of decline in the apo-B specific activity in IDL was also significantly reduced during infusion of anti-HTGL as compared to the controls, indicative of a reduction of IDL catabolism. The increase in IDL $\left(\mathrm{S}_{\mathrm{f}} 12-20\right)$ lipoproteins as determined by analytical ultracentrifugation, indicates that the decrease in IDL catabolism was greater than the reduced input from VLDL.

The data from the analytical ultracentrifuge suggest that HTGL may be involved in the conversion of a larger and less dense LDL to the more common $\mathrm{S}_{\mathrm{f}} \mathrm{0}_{-}$ $9 \mathrm{LDL}$. Such a role for HTGL is also compatible with a number of clinical observations. Women have lower mean HTGL levels (32) and larger quantities of the more rapidly floating LDL than do men (33). An increase in light LDL is inversely correlated with HTGL activity as measured in the postheparin plasma of distance runners (34).

$\mathrm{HDL}_{2}$ phospholipids and total mass increased in both the experimental and control animals. The lack of clear changes in HDL may relate to the acute nature of these experiments. Similar experiments performed in rats have demonstrated a rise in HDL phospholipids (11-13) that was confined to the $\mathrm{HDL}_{2}$ density range. In one of these studies (13), an increase in VLDL clearly preceded the changes in HDL. HTGL has been postulated to be the principal enzyme removing phospholipid from $\mathrm{HDL}_{2}$, thus converting those particles to the more dense $\mathrm{HDL}_{3}$. In view of the present findings, it is possible that the changes observed in the rat may have been secondary to altered metabolism of the lower density lipoproteins. We postulate that during degradation of triglyceride-rich lipoproteins by HTGL, surface components may be directly taken up by the liver. This process could involve apolipoprotein $\mathrm{E}$, a component of VLDL, for which there is a specific receptor on the hepatocyte $(35,36)$. By contrast, surface components released by LPL in peripheral tissues may be transferred to HDL (37). Thus, if the two enzymes act in parallel, inhibition of HTGL would lead to in- creased degradation of VLDL by LPL and the transfer of a larger mass of lipids and apoproteins HDL. This hypothesis would predict a rise in $\mathrm{HDL}_{2}$ without the need to propose a reduction in its conversion to $\mathrm{HDL}_{3}$.

LPL may be most active with chylomicrons and larger VLDL that are rich in C apolipoproteins, whereas HTGL may be particularly important in the catabolism of particles that are deficient in the $\mathrm{C}$ apolipoproteins (including apolipoprotein $\mathrm{CII}$, the activator of LPL). Compatible with this hypothesis, are the recent reports of reduced hepatic metabolism of VLDL and other triglyceride-rich lipoproteins after addition of a source of $\mathrm{C}$ apolipoproteins $(38,39)$. Although LPL can convert VLDL to LDL in vitro (40), this degradative process may be heavily shared with HTGL in vivo. Such a parallel role for HTGL is consistent with the continued metabolism of VLDL and the production of some LDL by human subjects with primary lipoprotein lipase deficiency (41-43).

\section{ACKNOWLEDGMENTS}

The authors would like to thank Dr. Patsy Wang-Iverson for providing the tri-[ $\left.\mathrm{H}^{3}\right]$ oyleoglycerol-labeled VLDL, Tibor Szabo, D.V.M. for multiple helpful suggestions, and Mrs. Marion Shiffer for assisting in preparation of this manuscript.

Supported in part by grants HL 28765, HL 23077, HL 22967, HL 18574, and Postdoctoral Research Service Award HL 06157 from the National Institutes of Health. Dr. Goldberg is a recipient of a Clinician-Scientist Award from the American Heart Association and its local affiliate, the New York Heart Association. Dr. Le is supported in part by postdoctoral traineeship HL 07343 awarded to the Division of Arteriosclerosis, College of Physicians \& Surgeons, Columbia University, New York.

\section{REFERENCES}

1. Cooper, A. D. 1979. The metabolism of chylomicron remnants by isolated perfused rat liver. Biochim. Biophys. Acta. 488: 464-474.

2. Berman, M., M. Hall III, R. I. Levy, S. Eisenberg, D. W. Bilheimer, R. D. Phair, and R. H. Goebel. 1978. Metabolism of apo-B and apo-C lipoproteins in man. Kinetic studies in normal and hyperlipoproteinemic subjects. $J$. Lipid Res. 19: 38-56.

3. Jensen, G. L., D. L. Bacy, P. M. Brannon, and A. Bensadoun. 1980. Synthesis and secretion of lipolytic enzymes by cultured chicken hepatocytes. J. Biol. Chem. 253: $11141-11148$

4. Kuusi, T., E. A. Nikkila, I. Virtanen, and P. K. J. Kinnunen. 1979. Localization of the heparin releasable lipase in situ in the rat liver. Biochem. J. 181: 245-246.

5. LaRosa, J. E., R. I. Levy, H. G. Windmueller, and D. S. Fredrickson. 1972. Comparison of the triglyceride lipase of liver, adipose tissue and postheparin plasma. J. Lipid Res. 13: 356-363.

6. Ehnholm, C., W. Shaw, H. Greten, and W. V. Brown. 1975. Purification from human plasma of a heparin-released lipase with activity against triglyceride and phospholipids. J. Biol. Chem. 250: 6750-6751.

7. Musliner, T. A., P. N. Herbert, and M. J. Kingston. 1979. Lipoprotein substrates of lipoprotein lipase and hepatic triacylglycerol lipase from human postheparin plasma. Biochim. Biophys. Acta. 575: 277-288. 
8. Muller, P., R. Fellin, J. Lambrecht, B. Agostini, H. Wieland, W. Rost, and D. Seidel. 1974. Hypertriglyceridemia secondary to liver disease. Eur. J. Clin. Invest. 4: 419-428.

9. Krauss, R. M., R. I. Levy, and D. S. Fredrickson. 1974. Selective measurement of two lipase activities from postheparin plasma from normal subjects and patients with hyperlipoproteinemia. J. Clin. Invest. 54: 1107-1124.

10. Mordasini, R., F. Frey, W. Flury, G. Klose, and H. Greten. 1977. Selective deficiency of hepatic triglyceride lipase in uremic patients. N. Engl. J. Med. 297: 13621366.

11. Kuusi, T., P. K. J. Kinnunen, and E. A. Nikkila. 1979. Hepatic endothelial lipase antiserum influences rat plasma low and high density lipoproteins in vivo. FEBS (Fed. Eur. Biochem. Soc.) Lett. 104: 384-388.

12. Jansen, H., A. van Tol, and W. C. Hulsmann. 1980. On the metabolic function of heparin releasable liver lipase. Biochem. Biophys. Res. Commun. 92: 53-59.

13. Grossen, J., O. Schrecker, and H. Greten. 1981. Function of hepatic triglyceride lipase in lipoprotein metabolism. J. Lipid Res. 22: 437-442.

14. Faegerman, O., T. Sata, J. P. Kane, and R. J. Havel. 1975. Metabolism of apoprotein B of plasma very low density lipoproteins in the rat. J. Clin. Invest. 56: 13961403.

15. Turner, P. R., N. E. Miller, C. Cortese, W. Hazzard, J. Coltart, and B. Lewis. 1981. Splanchnic metabolism of plasma apolipoprotein B. Studies of artery-hepatic vein differences of mass and radiolabel in fasted human subjects. J. Clin. Invest. 67: 1678-1686.

16. Goldberg, I. J., N-A. Le, H. N. Ginsberg, J. R. Paterniti, and W. V. Brown. 1981. Evidence for direct production of apolipoprotein B in low density lipoprotein in the cynomolgus monkey. Arteriosclerosis. 1: 378. (Abstr.)

17. Augustin, J., H. Freeze, P. Tejada, and W. V. Brown. 1978. A comparison of molecular properties of hepatic triglyceride lipase and lipoprotein lipase from human postheparin plasma. J. Biol. Chem. 253: 2912-2920.

18. Baginsky, M. L., and W. V. Brown. 1979. A new method for the measurement of lipoprotein lipase in postheparin plasma using sodium dodecyl sulfate for the inactivation of hepatic triglyceride lipase. J. Lipid Res. 20: 548-556.

19. Weir, D. M. 1978. Handbook of Experimental Immunology. Blackwell Scientific Publications, London. 1: 7.5-7.7.

20. Fielding, C. J. 1979. Validation of a procedure for exogenous isotopic labeling of lipoprotein triglyceride with radioactive triolein. Biochim. Biophys. Acta. 573: 255265.

21. Boberg, J., J. Augustin, M. L. Baginsky, P. Tejada, and W. V. Brown. 1977. Quantitative determination of hepatic and lipoprotein lipase from human postheparin plasma. J. Lipid Res. 18: 544-547.

22. Lowry, O. H., N. J. Rosebrough, A. L. Farr, and R. J. Randall. 1951. Protein measurement with the Folin phenol reagent. J. Biol. Chem. 193: 267-275.

23. Havel, R. J., H. A. Eder, and J. H. Bragdon. 1955. The distribution and chemical composition of ultracentrifugally separated lipoproteins in human serum. J. Clin. Invest. 34: 1345-1353.

24. Bligh, E. G., and W. J. Dyer. 1959. A rapid method of total lipid extraction and purification. Can. J. Biochem. Phys. 37: 911-917.

25. Chalvardjian, A., and E. Rudnicki. 1970. Determination of lipid phosphorus in the nanomolar range. Anal. Biochem. 36: 225-226.
26. Duck-Chung, C. 1979. A rapid sensitive method for determining phospholipid phosphorus involving digestion with magnesium nitrate. Lipids. 14: 492-497.

27. Ewing, A. M., N. K. Freeman, and F. T. Lindgren. 1965. The analysis of human serum lipoprotein distribution. Adv. Lipid Res. 3: 26-61.

28. Lindgren, F., L. C. Jensen, and F. T. Hatch. 1972. The isolation and quantitative analysis of serum lipoproteins. In Blood Lipids and Lipoproteins. G. J. Nelson, editor. John Wiley \& Sons, Inc., New York. 181-274.

29. Macfarlane, A. S. 1958. Efficient trace labeling of proteins with iodine. Nature (Lond.). 182: 53

30. Bilheimer, D. W., S. Eisenberg, and R. I. Levy. 1972. The matabolism of very low density lipoprotein proteins. 1. Preliminary in vitro and in vivo observations. Biochim. Biophys. Acta. 260: 212-221.

31. Le, N-A., J. S. Melish, B. C. Roach, H. N. Ginsberg, and W. V. Brown. 1978. Direct measurement of apoprotein B specific activity in ${ }^{125}$ I labeled lipoproteins. J. Lipid Res. 19: 578-584.

32. Huttunen, L. V., C. Ehnholm, M. Kekki, and E. A. Nikkila. 1977. Postheparin plasma lipoprotein lipase and hepatic lipase in normal human subjects relationship to age, sex and triglyceride metabolism. Adv. Exp. Med. Biol. 82: 146-148.

33. Krauss, R. M., F. T. Lindgren, and R. M. Ray. 1980. Interrelations among subgroups of serum lipoproteins in normal human subjects. Clin. Chim. Acta. 104: 275-290.

34. Krauss, R. M., P. D. Wood, C. Giotas, D. Waterman, and F. T. Lindgren. 1979. Heparin released plasma lipase levels in distance runners. Circulation. Suppl. 2, II-72 (Abstr).

35. Kovanen, P. T., M. S. Brown, and J. L. Goldstein. 1979. Increased binding of low density lipoprotein to liver membranes from rat treated with 17 alpha estradiol. $J$. Biol. Chem. 254: 11367-11373.

36. Mahley, R. W., D. Y. Hui, T. L. Innerarity, and K. H. Weisgraber. 1981. Two independent lipoprotein receptors on hepatic membranes of dog, swine and man. $J$. Clin. Invest. 68: 1197-1206.

37. Eisenberg, S., and T. Olivecrona. 1979. Very low density lipoprotein. Fate of phospholipids, cholesterol and apoprotein C during lipolysis in vitro. J. Lipid Res. 20: 614623.

38. Berry, E. M., R. Aldini, H. Bar-On, and S. Eisenberg. 1981. Role of the liver in degradation of very low density lipoproteins. A study of lipolysis by heparin releasable liver lipase and uptake during isolated rat liver perfusion. Eur. J. Clin. Invest. 11: 151-159.

39. Windler, E., Y. Chao, and R. J. Havel. 1980. Regulation of the hepatic uptake of triglyceride rich lipoproteins in the rat. J. Biol. Chem. 255: 8303-8307.

40. Deckelbaum, R. J., S. Eisenberg, M. Fainaru, L. Barelholz, and T. Olivecrona. 1979. In vitro production of human plasma low density lipoprotein like particles. $J$. Biol. Chem. 254: 6079-6087.

41. Quarfordt, S. H., A. Frank, D. M. Shames, M. Berman, and D. Steinberg. 1970. Very low density lipoprotein triglyceride transport in Type IV hyperlipoproteinemia and the effects of carbohydrate-rich diets. J. Clin. Invest. 49: 2281-2297.

42. Ford, S., Jr., W. K. Schubert, C. J. Glueck, and R. C. Bozian. 1971. Familial hyperchylomicronemia. Am. J. Med. 50: 536-541.

43. Nicoll, A., and B. Lewis. 1980. Evaluation of the roles of lipoprotein lipase and hepatic lipase in lipoprotein metabolism in vivo and in vitro studies. Eur. J. Clin. Invest. 10: 487-495. 